\title{
A Kampo (Traditional Japanese Herbal) Medicine, Hochuekkito, Pretreatment in Mice Prevented Influenza Virus Replication Accompanied with GM-CSF Expression and Increase in Several Defensin mRNA Levels
}

\author{
Katsuaki Dan ${ }^{a}$ Hiroko Akiyoshi $^{b}$ Kaori Munakata $^{\mathrm{b}}$ Hideki Hasegawa $^{\mathrm{c}}$ \\ Kenji Watanabe ${ }^{b}$ \\ ${ }^{a}$ Collaborative Research Resources, Core Instrumentation Facility, and ${ }^{b}$ Center for Kampo Medicine, Keio University \\ School of Medicine, and ' Department of Pathology, National Institute of Infectious Diseases, Tokyo, Japan
}

\section{Key Words}

Influenza virus · Hochuekkito · Granulocyte-macrophage

colony-stimulating factor $\cdot$ Defensin

\begin{abstract}
A Kampo medicine, Hochuekkito (TJ-41), with an influenza virus-preventing effect had life-extending effectiveness, and immunological responses other than interferon (IFN)-a release were examined. TJ-41 $(1 \mathrm{~g} / \mathrm{kg})$ was given to C57BL/6 male mice orally once a day for 2 weeks. Mice were then intranasally infected with influenza virus. After infection, virus titers and various parameters, mRNA levels and protein expression, for immunoresponses in the bronchoalveolar lavage fluid or removed lung homogenate, were measured by plaque assay, quantitative RT-PCR and ELISA. IFN- $\alpha$ and - $\beta$ levels of TJ-41-treated mice were higher than those of the control. Toll-like receptor TLR7 and TLR9 mRNAs were elevated after infection, but retinoic acid-inducible gene (RIG-1) family mRNA levels, RIG-1, melanoma differentiation-associated gene 5 and Leishmania $\mathrm{G}$ protein 2 showed no response in either TJ-41 or control groups. Interferon regulatory transcription factor (IRF)-3 mRNA levels to stimulate type I ( $\alpha / \beta)$ IFN were increased, but IRF-7 did not change. Only granulo-
\end{abstract}

cyte-macrophage colony-stimulating factor (GM-CSF) after Hochuekkito treatment was significantly elevated 2 and 3 days after infection. The mRNA levels of 7 defensins after infection increased compared to preinfection values. The key roles of TJ-41 were not only stimulation of type I IFN release but also GM-CSF-derived anti-inflammation activity. Furthermore, defensin (antimicrobial peptide) mRNA levels increased by infection and were further enhanced by TJ-41 treatment. Defensin might prevent influenza virus replication.

Copyright $\odot 2013$ S. Karger AG, Basel

\section{Introduction}

Traditional herbal medicines have been used to treat almost all infectious diseases for more than 2,000 years in China. In Japan, some of these herbal medicines (Kampo) have been used clinically for various diseases as well as infectious diseases. It has been confirmed that Kampo medicine possesses various virological activities [1-8].

Pandemic influenza A virus has long been a public health threat. Selected herbal medicines, Maoto and Hochuekkito (Hochu, TJ-41), were clinically effective against influenza infectious disease [8], although details of the

\section{KARGER}

E-Mail karger@karger.com www.karger.com/pha
(C) 2013 S. Karger AG, Basel

0031-7012/13/0916-0314\$38.00/0 
immune response kinetics against influenza virus infection were not elucidated.

TJ-41 possesses several biological activities and enhances host immunoresponses in animal experiments. Mori et al. [9] reported that TJ-41 elevated the levels of interferon (IFN)- $\alpha$ in bronchoalveolar lavage fluid (BALF) on day 2 after infection. Subsequently, the immunodefense mechanism against virus infection was elucidated $[9,10]$. The cell-signaling route in immunomediated cells for various virus infections, including influenza virus, and the direct action with an antimicrobial peptide, defensin, have been clarified in recent years and cannot be explained by the secretion of IFN- $\alpha$ alone $[11,12]$.

Anti-influenza virus activity was tested using the $\mathrm{Balb} / \mathrm{c}$ mouse strain. In the present report, our purpose was to confirm the survival rate of another mouse strain, C57BL/6, and to clarify the main mediator which responds to influenza virus infection with IFN- $\alpha$. To clarify the cell-signaling mechanism in the cell, we administered high-dose TJ-41 to the mice.

On the other hand, defensin peptides are known for their broad-spectrum antimicrobial activity [13-18].

We have already found that the defensin mRNA level in the spleen increased when TJ-41 was administered to normal mice (data not shown). We determined whether defensin mRNA in mouse lung after infection changes with the effect of TJ-41 pretreatment.

\section{Materials and Methods}

\section{Animals}

Male C57BL/ 6 mice at the age of 6 weeks were purchased from Charles River Japan Inc. The mice were given food and water ad libitum and kept in an air-controlled cabinet at $23 \pm 1{ }^{\circ} \mathrm{C}$ with 55 $\pm 5 \%$ relative humidity for 1 week until the time of infection.

\section{Herbal Medicine}

Hochuekkito (TJ-41), consisting of spray-dried hot water extracts of 10 medicinal plants, was kindly supplied by Tumura \& Co. (Tokyo, Japan). TJ-41 consists of astragali radix (16.7\%), Atractylodes lancea rhizoma (16.7\%), Ginseng radix (16.7\%), angelicae radix $(12.5 \%)$, bupleuri radix $(8.3 \%)$, zizyphi fructus $(8.3 \%)$, aurantii nobilis pericarpium (8.3\%), glycyrrhizae radix (6.3\%), cimicifugae rhizoma (4.2\%) and zingiberis rhizoma (2.0\%). The chemical profile of TJ-41 obtained by 3 -dimensional high-performance liquid chromatography (HPLC) analysis is shown in figure 1 . The HPLC condition was as follows: column TSK Gel ODS-80TS column $250 \times 4.6 \mathrm{~mm}$ (Tosoh, Tokyo, Japan). The solvents were (A) $0.05 \mathrm{~mol} / \mathrm{l}$ ammonium acetate-acetic acid buffer $(\mathrm{pH} 3.6)$ and $(\mathrm{B})$ $100 \%$ acetonitrile. A linear gradient of $90 \% \mathrm{~A}$ and $10 \% \mathrm{~B}$ changing over $1 \mathrm{~h}$ to $0 \% \mathrm{~A}$ and $100 \% \mathrm{~B}$ was applied $(0 \% \mathrm{~A}$ and $100 \% \mathrm{~B}$ was continued for $20 \mathrm{~min}$ ). The flow rate and the column temperature were $1.0 \mathrm{ml} / \mathrm{min}$ at $40^{\circ} \mathrm{C}$, respectively. The UV data of the effluent from the column ranging from 200 to $420 \mathrm{~nm}$ was collected, and the peak analysis and assignment were performed using the system analysis software CLASS-LC10 (Shimadzu).

\section{Chemicals}

All chemicals were purchased from Wako Jyunyaku Inc.

\section{Virus}

Influenza $\mathrm{A} / \mathrm{PR} / 8 / 34(\mathrm{H} 1 \mathrm{~N} 1)$ virus and vesicular stomatitis virus were provided by the National Institute of Infectious Diseases and the Ministry of Agriculture, Forestry and Fisheries, respectively.

A pool of influenza virus was initially prepared in the allantoic cavity of fertilized pathogen-free hen eggs. Virus titers were determined by plaque assay on Madin-Darby canine kidney cells and expressed as plaque-forming units [19].

\section{Cell Lines}

Madin-Darby canine kidney and L-929 cells were maintained in Dulbecco's modified Eagle's medium supplemented with $10 \%$ heat-inactivated fetal bovine serum, penicillin $(100 \mathrm{U} / \mathrm{ml})$, streptomycin $(100 \mu \mathrm{g} / \mathrm{ml})$, and kanamycin $(10 \mu \mathrm{g} / \mathrm{ml})$.

\section{Virus Infection}

Male C57BL/6 mice at the age of 9 weeks were intranasally infected with influenza virus in a volume of $0.1 \mathrm{ml}$ at a dose of $5 \times$ $10^{6}$ plaque-forming units/head $\left(2 \times \mathrm{LD}_{50}\right)$. According to the animal experimentation guidelines of Keio University School of Medicine, infected mice were kept in a biohazard cabinet and allowed food and water ad libitum throughout the experiments.

\section{Experimental Design and Estimations}

Experiment 1: Survival Test

TJ-41 (1,000 mg/kg) was given to mice orally once a day for 2 weeks. Two $\mathrm{LD}_{50}$ doses of influenza virus were inserted intranasally.

Mouse survival and mortality were assessed for 2 weeks.

Experiment 2: Estimation of Effects of TJ-41

As in experiment 1, TJ-41-pretreated mice were infected with influenza virus intranasally.

Lung tissues were removed from the mouse to the target with BALF at the time of euthanasia. Each lung was cut into pieces and divided into 3 groups for several assays. Total RNA was extracted from one group using TRIzol reagent (Invitrogen), and $1 \mu \mathrm{g}$ of total RNA was reverse-transcribed into cDNA using a mixture of random primer and Superscript III reverse transcriptase under the recommended conditions (Invitrogen). Part of the lungs was homogenized for protein extraction and another was suspended in $1 \%$ bovine serum albumin containing Hanks' balanced salt solution for virus titration using the plaque assay method. Two BALF samples were stored at $-80^{\circ} \mathrm{C}$ until the plaque assay and IFN- $\alpha$ assay, respectively.

\section{IFN- $\alpha$ Biological Activity Assay}

The IFN activity showed vesicular stomatitis virus in L-929 cells by virus infection interference when it was infected [20]. 


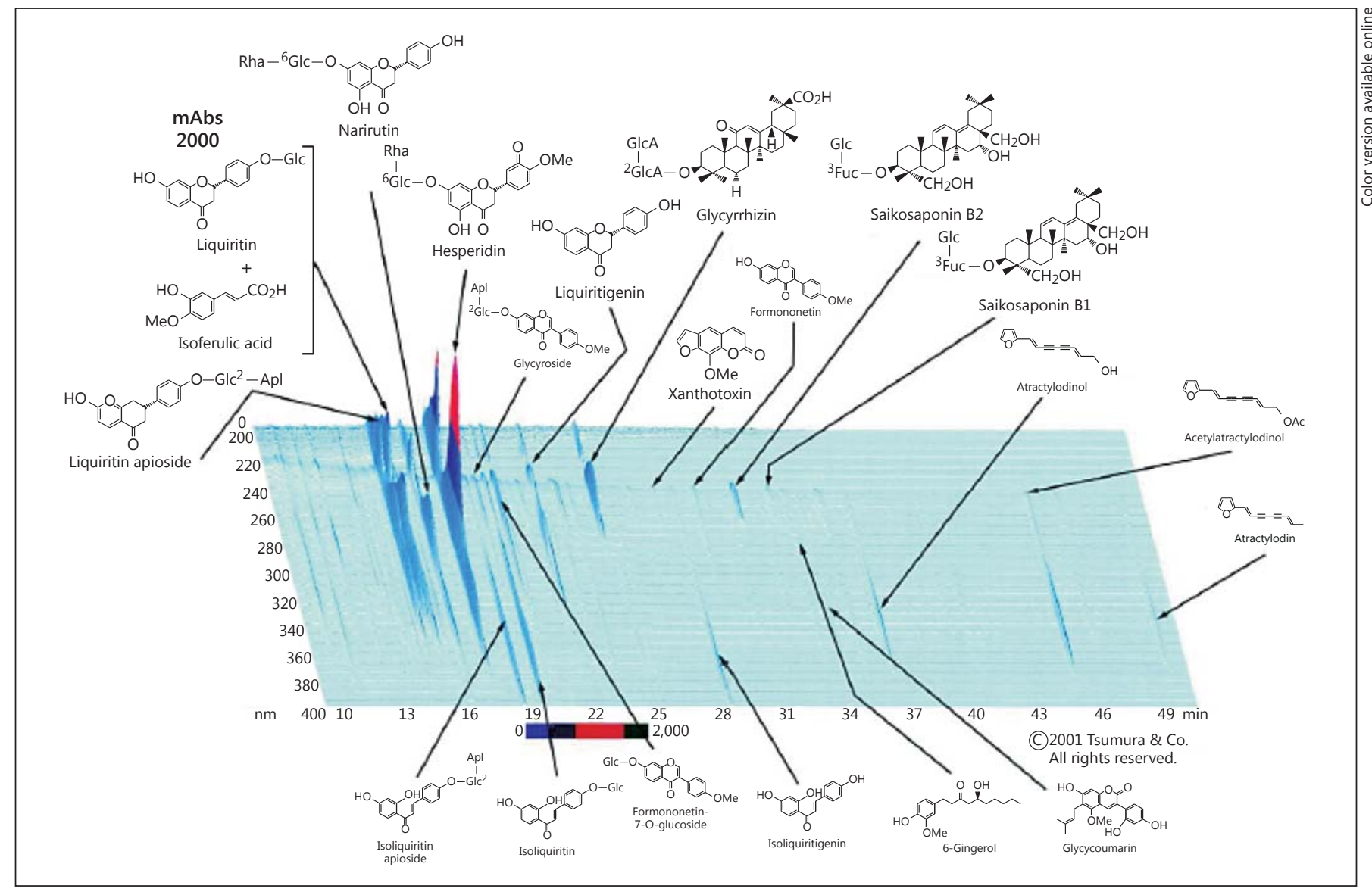

Fig. 1. Chemical profile of TJ-41 analyzed by 3-dimensional HPLC. Each peak of TJ-41 in the HPLC profile was identified by comparison of the retention times and UV spectra of chemically defined standard compounds. $\mathrm{mAbs}=$ Monoclonal antibodies .

\section{Semiquantitative RT-PCR}

Quantitative RT-PCR was carried out using the Step One Plus Fast Real-Time PCR system with fast SYBR Green Master Mix (Applied Biosystems). The relative abundance of mRNA was obtained by calculating the difference in threshold cycles of the target and control samples, commonly known as the $\Delta \Delta \mathrm{C}_{\mathrm{T}}$ method, using glyceraldehyde-3-phosphate dehydrogenase for normalization. Primers used to detect IFN- $\beta$, Toll-like receptor (TLR)7, TLR9, retinoic acid inducible gene (RIG)-1, melanoma differentiation-associated protein (MDA) 5, Leishmania G protein 2 (LGP2), interferon regulatory transcription factor (IRF)-3, IRF-7, I $\kappa \mathrm{B}$ kinase $\gamma$-subunit (IKK $\gamma$ ), nuclear factor (NF)- $\kappa B$, $\alpha$-defensins $1,3,4$, 5 and $\beta$-defensins $1,2,3,4$, are indicated in table 1 [21-27]. $\Delta \mathrm{C}_{\mathrm{T}}$ was obtained based on the $\mathrm{C}_{\mathrm{T}}$ value of the control group compared to the infected group.

\section{Mouse Cytokine Assay}

A Mouse Cytokine Magnetic 10-Plex Panel Kit (Invitrogen) and Luminex Detection system were used for the quantitative determination of granulocyte-macrophage colony-stimulating factor (GM-CSF), IFN- $\gamma$, interleukin (IL)-1 $\beta$, IL-2, IL-4, IL-5, IL-6, IL-10, IL-12 and tumor necrosis factor- $\alpha$ in lung homogenates.

\section{Statistical Analysis}

Data are expressed as the mean \pm SD. Significant differences were evaluated by Student's t test.

\section{Results}

Pretreatment Effect of TJ-41 on Mouse Survival after Influenza Virus Infection

Mouse survival was determined until 14 days after infection. As shown in figure 2, the survival rate of TJ41 -pretreated mice was $90 \%$, higher than the virus control, with a $54 \%$ survival. 


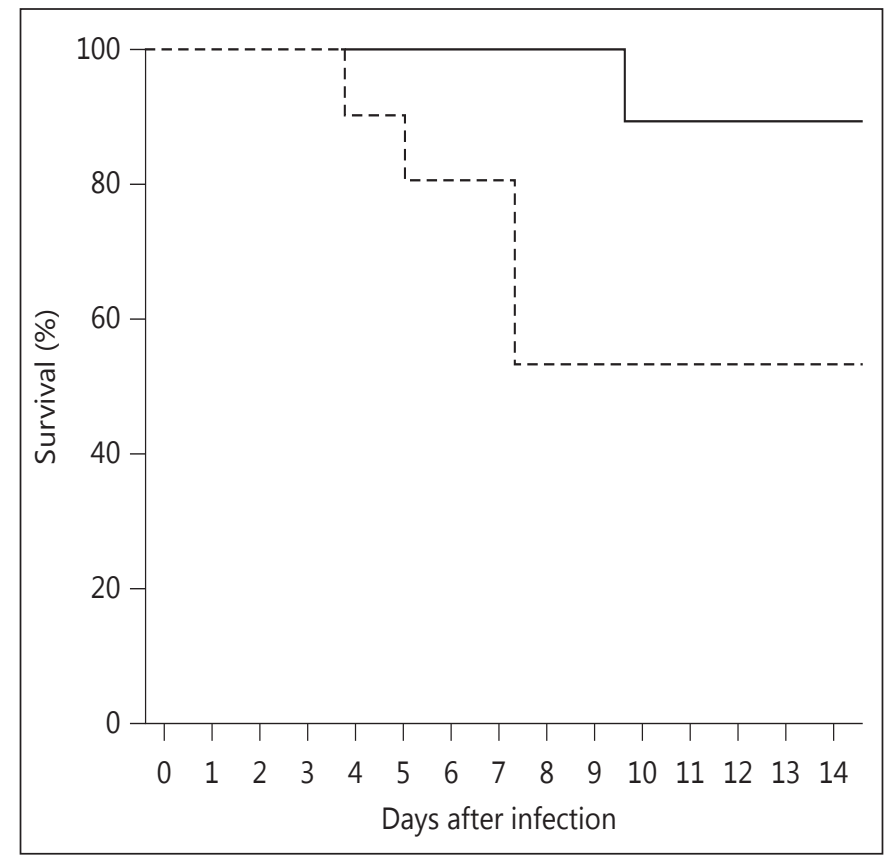

Fig. 2. Effect of TJ-41 on the survival of influenza virus-infected mice. TJ-41 at a dose of $1 \mathrm{~g} / \mathrm{kg}$ was administered orally once daily for 2 weeks before infection. Solid line = virus control; dotted line $=\mathrm{TJ}-41$ treatment.

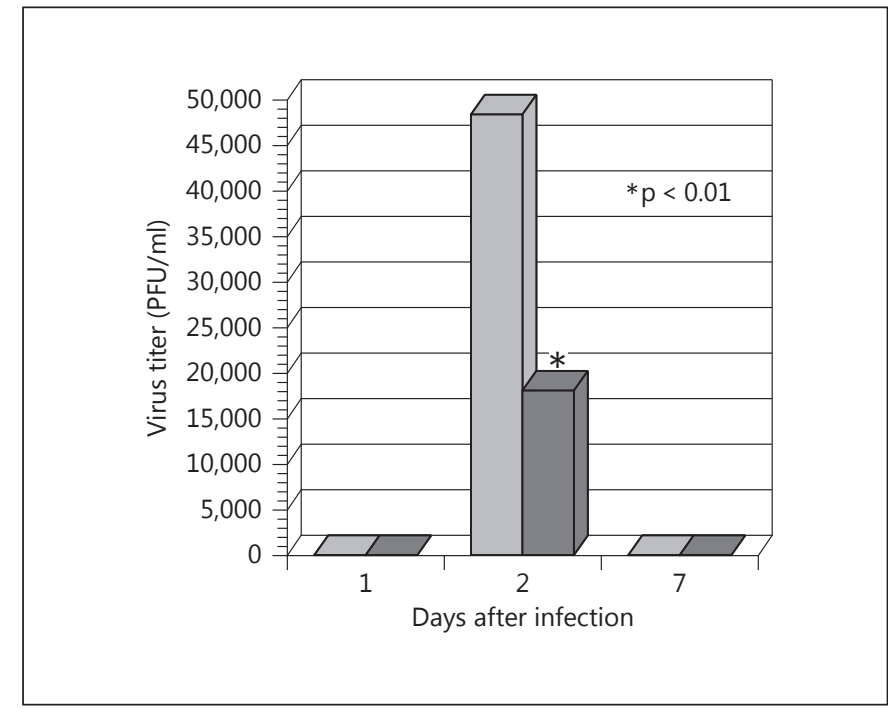

Fig. 3. Influenza virus titer in the BALF of infected mice administered TJ-41 or water. TJ-41 at a dose of $1 \mathrm{~g} / \mathrm{kg}$ was administered orally once daily for 2 weeks before infection. BALF samples were obtained from virus-infected mice on days 1, 2, and 7 after infection. Data are expressed as the control (light gray column) and TJ41 (dark gray column). Virus titers represent the means of data obtained from 6 mice. ${ }^{*} \mathrm{p}<0.01$ compared with control mice on each day after infection.

Table 1. Primers for PCR

\begin{tabular}{|c|c|c|}
\hline Gene & Forward primer & Reverse primer \\
\hline IFN- $\beta$ & CTGGAGCAGCTGAATGGAAAG & СTTCTCCGTCATCTCCATAGGG \\
\hline TLR7 & AGAGGCCCATGTGATCGTG & CGAGGGCAATTTCCACTTAGG \\
\hline TLR9 & AACATGGTTCTCCGTCGAAGG & GTAGTAGCAGTTCCCGTCC \\
\hline RIG-1 & AAAGCCAGAGACCAAGACCA & TATCTCCGCTGGCTCTGAAT \\
\hline MDA5 & TGACGAGTGTCTCCACTTGC & TCCATTTGGTAAGGCVTGAG \\
\hline LGP2 & CTTTGACTTCCTGCAGCATT & CAATGAGGTGGTCAGTCCAG \\
\hline IRF-3 & GTGCCTCTCCTGACACCAAT & CCAAGATCAGGCCATCAAAT \\
\hline IRF-7 & CTGGAGCCATGGGTATGCA & AAGCACAAGCCGAGACTGCT \\
\hline $\mathrm{IKK} \gamma$ & GCACCTGCCTTCAGAACAGG & ATCTGGTTGCTCTGCCGG \\
\hline$N F-\kappa B$ & AGGCTTCTGGGCCTTATGTG & TGCTTCTCTCGCCAGGAATAC \\
\hline a-Defensin 1 & AGAGCTGCCTGCTCATCCTAATC & TCATGCTCGTCTTGTTCTCTGTG \\
\hline a-Defensin 3 & TCСТCСТCTCTGCCСTCGT & GACCCTTTCTGCAGGTCCC \\
\hline a-Defensin 4 & ACTTGICCTCCTCTCTGCCCT & TCGTATTCCACAAGTCCCACG \\
\hline a-Defensin 5 & ATTTGTCCTCCTCTCTGCССTT & AAAGATTTCTGCAGGTCCCAAA \\
\hline$\beta$-Defensin 1 & TCCTCTCTGCACTCTGGACC & ATCGCTCGTCCTTTATGTCC \\
\hline$\beta$-Defensin 2 & CСTTTCTACCAGCCATGAGG & GCAACAGGGGTTCTTCTCTG \\
\hline$\beta$-Defensin 3 & CTCCACCTGCAGCTTTTAGC & GCTAGGGAGCACTTGTTTGC \\
\hline$\beta$-Defensin 4 & CTCCACTTGCAGCCTTTACC & CATGGAGGAGCAAATCTGG \\
\hline
\end{tabular}


Virus Replication and IFN- $\alpha$ Activity in BALF from

Infected Mice (Experiment 2)

Hochu pretreatment prevented virus replication in BALF in the acute phase of infection (fig. 3). Virus titers of TJ-41-treated mouse BALF 2 days after infection were about $64 \%$ lower than the virus control titer. IFN- $\alpha$ in BALF from both TJ-41-treated and -untreated virus-infected mice was determined on days $0,1,2,3,4$ and 7 after infection. IFN- $\alpha$ levels in TJ-41-treated mice were higher than those of the control 4 days after infection, except day 7 (fig. 4). These results showed that TJ-41 pretreatment affects not only Balb/c mice, but also C57BL/6 mice.

\section{Innate Immunosystem against Virus Infection}

As shown in figure 5, the antivirus responses were type 1 IFN stimulation and NF- $\kappa \mathrm{B}$-derived cytokine release. After virus infection, influenza virus RNA was recognized by either TLR7 or TLR9 in the host cell endosome or cytoplasm RNA sensor, the RIG-1 family. Each TLR is involved in the downstream cell signaling by using an adaptor molecule, myeloid differentiation primary response protein (MyD88) or TIR-domain-containing adaptor-inducing interferon- $\beta$ (TRIF). On the other hand, RIG-like helicase (RLH) uses interferon promoter stimulator 1 (IPS-1) as an adaptor molecule. The IKK complex is activated by MyD88, and the production of proinflammatory cytokines is induced by NF- $\kappa \mathrm{B}$. TRIF and IPS- 1 induce IKK complexes and Tank-binding kinase 1 (TBK1)/IKKI activation. The production of type I IFN is induced by not only the gene expression causing NF- $\kappa \mathrm{B}$, but also IRF-3 and the antivirus gene group.

These mRNA responses after infection were determined using quantitative RT-PCR.

Intracellular Response of $m R N A$ Levels to Several Cell Signals after Infection and the Role of TJ-41

IFN- $\beta$ mRNA levels of Hochu increased compared to the control (fig. 6). TLR7 and TLR9 mRNA were elevated after infection (fig. 6), but RIG-1 family mRNA levels, RIG-1, MDA5, and LGP2, did not respond in either Hochu or control groups (fig. 6). With more downstream signaling, IRF-3 mRNA levels to stimulate type 1 IFN were increased, but IRF-7 did not change (fig. 6). For cytokine release, IKK $\gamma$ and NF- $\kappa \mathrm{B}$ mRNA levels responded to infection (fig. 6).

\section{Mouse Cytokine Level Estimation}

The release of several cytokines accompanied by the increase in NF- $\mathrm{BB}$ mRNA was estimated using a multiple

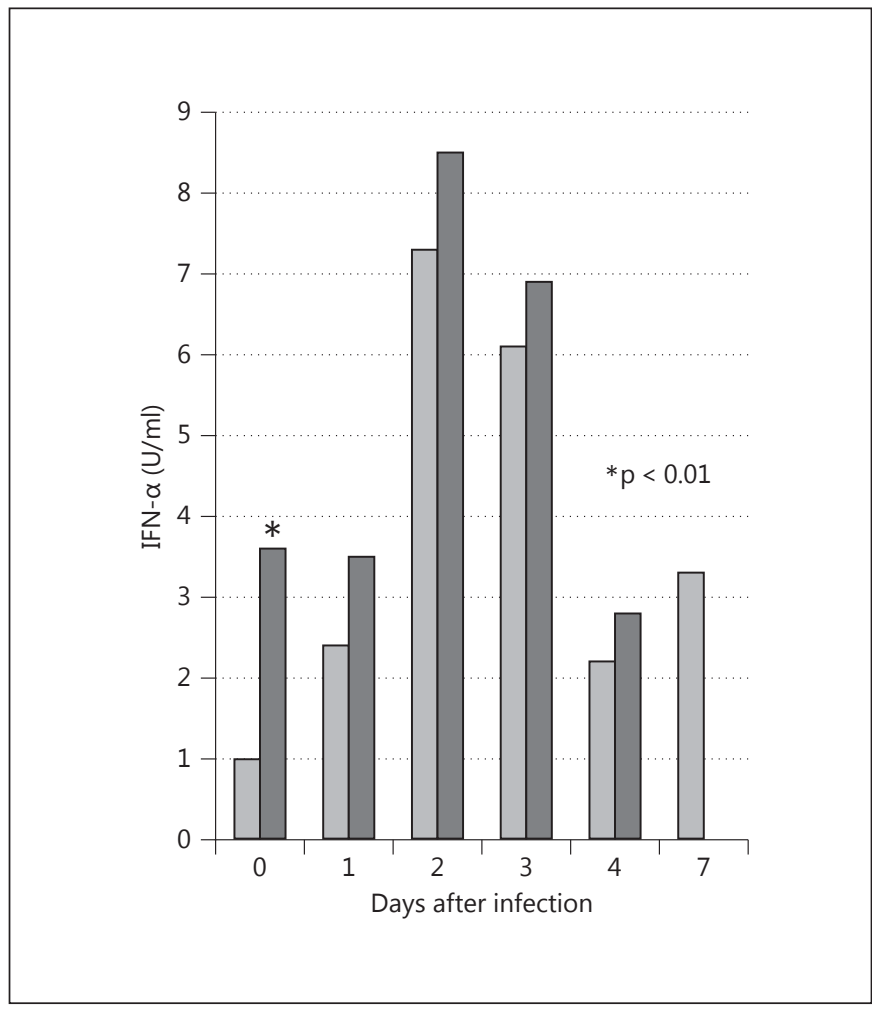

Fig. 4. IFN- $\alpha$ activity in the BALF of infected mice administered TJ-41 or water. TJ-41 at a dose of $1 \mathrm{~g} / \mathrm{kg}$ was administered orally once daily for 2 weeks before infection. BALF samples were obtained from virus-infected mice on days 1, 2, 3, 4 and 7 after infection. Data are expressed as virus control (light gray column) and TJ-41 (dark gray column). ${ }^{*} \mathrm{p}<0.01$ compared with control mice on each day after infection.

magnetic panel kit and a Luminex detection assay system (fig. 7). Seven types of IL, IL-1 $\beta, 2,4,5,6,10$ and 12 , and IFN- $\alpha$ and tumor necrosis factor- $\alpha$ tended to increase after infection, but were not significant between TJ-41 and the control. Only GM-CSF with TJ-41 treatment was significantly elevated 2 and 3 days after infection.

\section{Defensin mRNA Level Estimation}

We also determined whether several types of defensin mRNA levels changed before and after infection (fig. 8). Seven defensin mRNA levels increased after infection compared with preinfection values, except $\beta$-defensin 4 .

Almost all defensin mRNA levels after infection were increased by TJ- 41 pretreatment, but in the small intestine, several defensin mRNAs did not respond to virus infection (data not shown). 
Fig. 5. Schematic representation of innate immune systems against viral infection. Several mRNA levels after infection were estimated by quantitative RT-PCR.

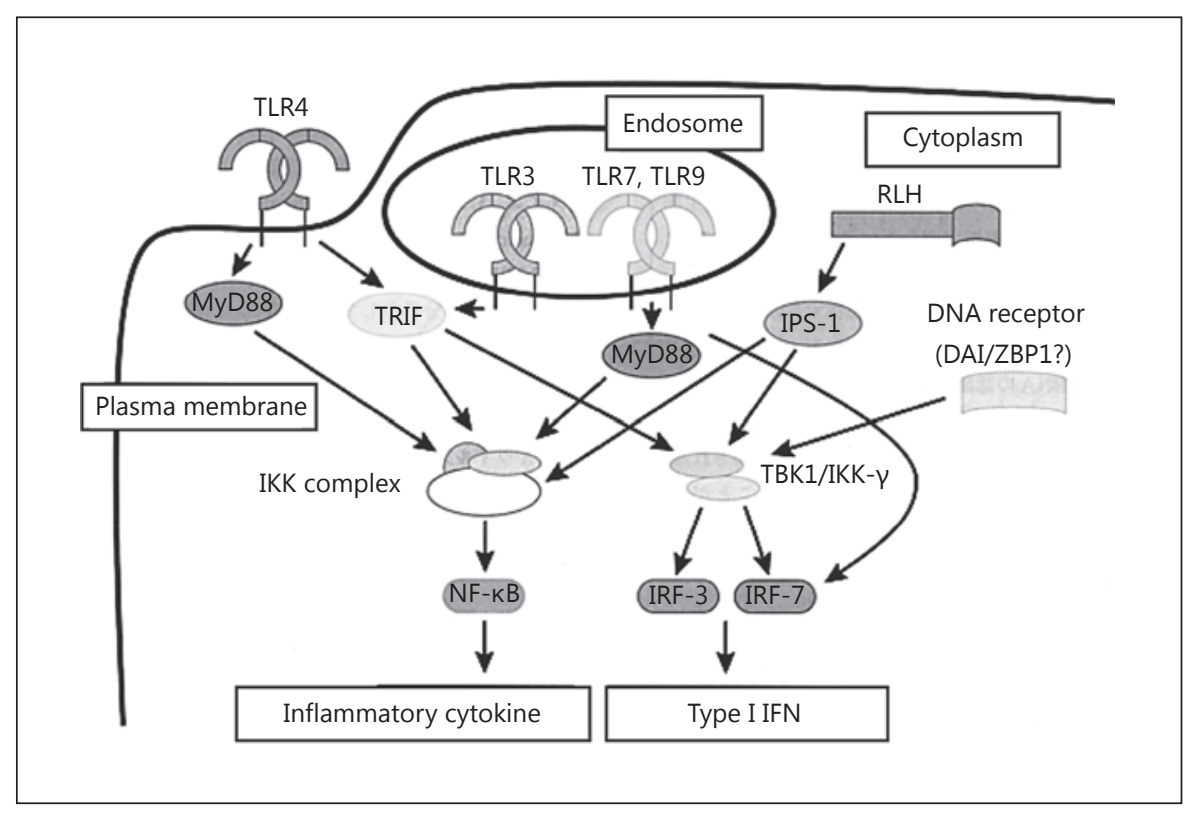

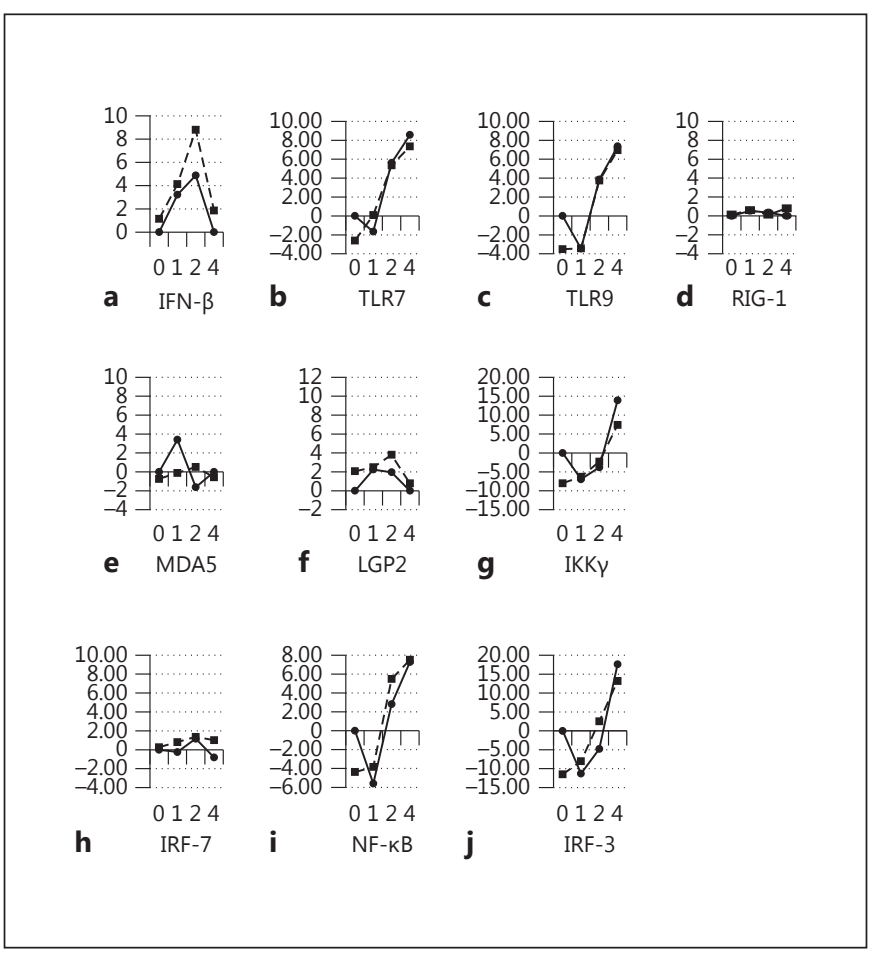

Fig. 6. Expression of several innate immune system-related genes against viral infection with quantitative RT-PCR. The genes were cytosolic receptors for viral RNA (RIG-1, MDA5, LGP2), Toll-like receptors (TLR7, TLR9), interferon regulatory factors (IRF-3, IRF$7, \mathrm{IKK} \gamma$ ), IFN- $\beta$ or cytokine regulatory factor (NF- $\kappa \mathrm{B})$. Gene expression is depicted relative to the expression in the control on day 0 . Closed circles show the control and squares show Hochu.

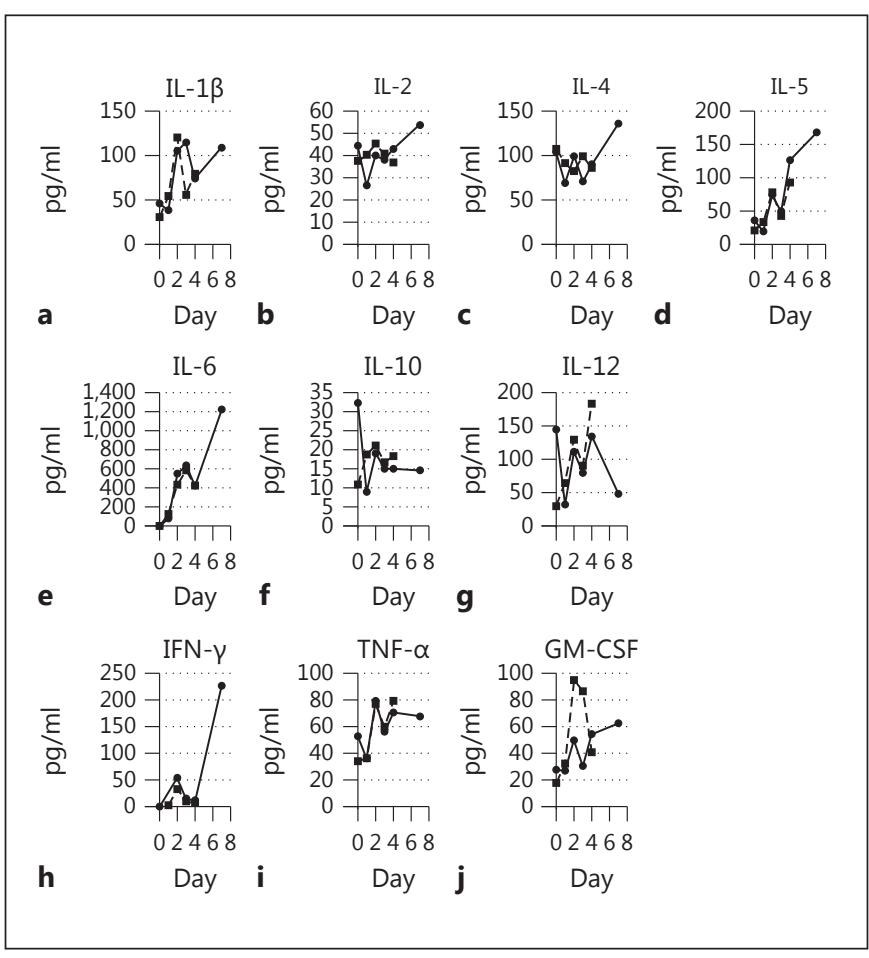

Fig. 7. Cytokine secretion during influenza virus infection in mouse lung tissues. Each cytokine level was measured with the multiple ELISA assay system. Closed circles show the control and squares show Hochu. 
Fig. 8. Antimicrobial peptide, defensin, subtype expression against TJ-41 administration or influenza virus infection with quantitative RT-PCR. Defensin subtypes were $\alpha$-types $1,3,4$ and 5, or $\beta$-types 1,2, 3 and 4 . Gene expression is depicted relative to the expression $\left(\Delta \Delta \mathrm{C}_{\mathrm{T}}\right)$ in the control on day $0.0-\mathrm{C}=\mathrm{Control}$ on day $0 ; 0-\mathrm{H}=\mathrm{TJ}-41$ on day $0 ; 1-\mathrm{C}=$ control 1 day after infection; $1-\mathrm{H}=\mathrm{TJ}-411$ day after infection.

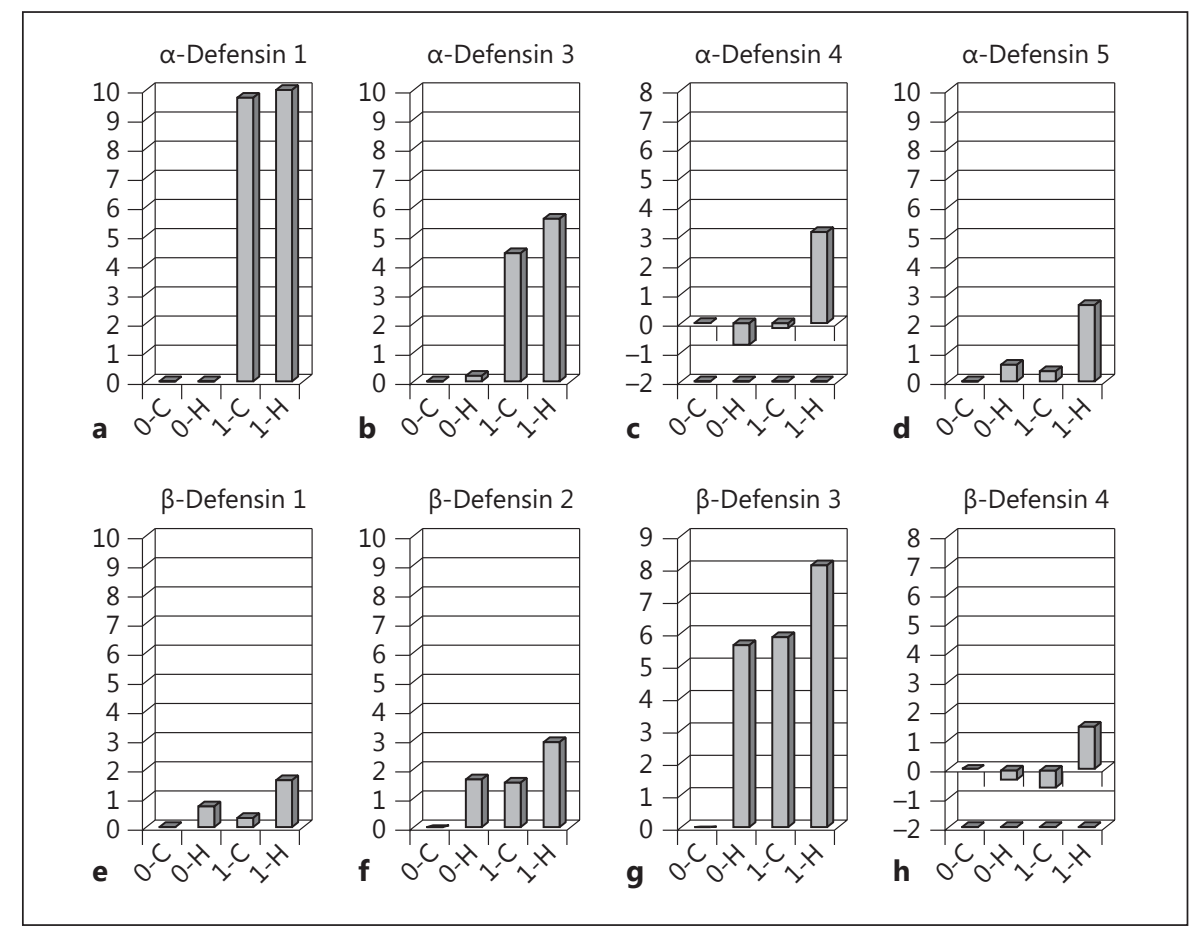

\section{Discussion}

It has already been clarified that Hochuekkito (TJ-41) pretreatment of $\mathrm{Balb} / \mathrm{c}$ mice inhibited influenza A virus replication by IFN- $\alpha$ upregulation [9].

In this article, we determined the following:

(1) whether Hochu pretreatment of another mouse strain (C57BL/6) inhibited influenza A virus replication;

(2) whether anti-influenza virus activity of TJ-41 depended only on IFN- $\alpha$ upregulation;

(3) whether an antimicrobial peptide, defensin, played a role in preventing influenza virus replication.

We have studied the immunity of the small intestine mainly using C57BL/6 mice, which were therefore used in these experiments.

(1) We confirmed that TJ-41 pretreatment of C57BL/6 mice also prevented influenza virus replication. After infection, mouse survival increased (fig. 2) and virus titers in BALF in Hochu-pretreated mice were lower than those of the control (fig. 3). IFN- $\alpha$ activity on day 0 in TJ-41-pretreated mouse BALF accumulated to that of the compared control. In the acute phase of infection, TJ-41 groups showed high biological activity of IFN- $\alpha$. These results corresponded to previous results using Balb/c mice. As IFN- $\alpha$ consists of several genes, IFN- $\alpha$ must be considered to have direct biological activity, not mRNA levels.
(2) We determined whether this anti-influenza virus activity was caused not only by IFN- $\alpha$ upregulation. Recently, cellular protection systems against virus infection have been developed gradually (fig. 5). Conventional dendritic cells or macrophages induced antivirus action, with type I IFN $(\alpha / \beta)$ release as the first step. In the second step, plasmacytoid dendritic cells induced immunoreactions depending on TLR activation [28]. RNA viruses such as influenza virus are recognized by TLR7 and TLR9 $[29,30]$.

As shown in figure 5, TLR7 and TLR9 mRNA levels were elevated after infection but RIG-1, MDA5, and LGP2 were not. The RIG-1 family may respond earlier than 1 day after infection, such as after several hours, IFN- $\beta$ and NF- $\kappa B$ also responded, so immunoresponses against viral infection involve both type I IFN upregulation and NF- $\mathrm{kB}$-derived cytokine release. TJ-41 pretreatment effects showed IFN $-\alpha / \beta$ but not other signals among the estimated mRNA levels.

Accordingly, as NF- $\kappa \mathrm{B}$ downstream signals, various cytokine levels in lung homogenate were determined using multiple kits and the Luminex detection system. Changes of almost all cytokine and transforming factor levels were not clear, but only GM-CSF levels with TJ-41 pretreatment were elevated significantly 2 and 3 days after infection. GM-CSF induced the activation and differen- 
tiation of T cells [31]; therefore, the key roles of TJ-41 were stimulation of type I IFN release and anti-inflammation activity, for instance $\mathrm{T}$ cell activation and differentiation.

(3) Furthermore, an antimicrobial peptide, defensin, inhibits influenza virus infection [13]. Almost all defensin mRNA levels responded to virus infection and were enhanced by TJ-41 pretreatment. In particular increased mRNA levels were observed by pre-administering TJ-41, as for $\beta$-defensins 1, 2 and 3. Defensin peptides might therefore prevent influenza virus replication. The action mechanism and active site of TJ-41 will be clarified in the near future.

\section{Acknowledgments}

This study was supported by grants from the Ministry of Education, Culture, Sports, Science and Technology (grant No. 23659386).

We thank the Core Instrumentation Facility, Keio University School of Medicine, for technical assistance.

\section{References}

1 Nagai T, Yamada H: In vivo anti-influenza virus activity of kampo (Japanese herbal) medicine 'sho-seiryo-to' and its mode of action. Int J Immunopharmacol 1994;16:605-613.

$\checkmark 2$ Nagai T, Urata M, Yamada H: In vivo antiinfluenza virus activity of kampo (Japanese herbal) medicine 'sho-seiryu-to'-effects on aged mice, against subtypes of $A$ viruses and $B$ virus, and therapeutic effect. Immunopharmacol Immunotoxicol 1996;18:193-208.

- 3 Mantani N, Andoh T, Kawamata H: Inhibition effect of ephedrae herba, an oriental traditional medicine, on the growth of influenza $\mathrm{A} / \mathrm{PR} / 8$ virus in MDCK cells. Antivir Res 1999;44:193-200.

4 Nagai T, Kiyohara H, Munakata K: Pinellic acid from the tuber of Pinellia ternata Breitenbach as an effective oral adjuvant for nasal influenza vaccine. Int Immunopharmacol 2002;2:1183-1193.

5 Murayama T, Yamaguchi N, Iwamoto K: Inhibition of ganciclovir-resistant human cytomegalovirus replication by Kampo (Japanese herbal medicine). Antivir Chem Chemother 2006; 17:11-16.

6 Hayashi K, Imanishi N, Kashiwayama Y: Inhibitory effect of cinnamaldehyde, derived from cinnamomi cortex, on the growth of influenza $\mathrm{A} / \mathrm{PR} / 8$ virus in vitro and in vivo. Antiviral Res 2007;74:1-8.

7 Kubo T, Nishimura H: Antipyretic effect of Mao-to, a Japanese herbal medicine, for treatment of type A influenza infection in children. Phytomedicine 2007;14:96-101.

$\checkmark 8$ Yasuda T, Yamaki M, Iimura A: Anti-influenza virus principles from Muehlenbeckia hastulata. J Nat Med 2010;64:206-211.

-9 Mori K, Kido T, Daikuhara H: Effect of Hochu-ekki-to (TJ-41), a Japanese herbal medicine, on the survival of mice infected with influenza virus. Antivir Res 1999;44:103-111.

10 Kiyohara H, Nagai T, Munakata K: Stimulating effect of Japanese herbal (Kampo) medicine, Hochuekkito on upper respiratory mucosal immune system. Evid Based Complement Alternat Med 2006;3:459-467.
11 Matsumoto T, Noguchi M, Hayashi O: Hochuekkito, a Kampo (traditional Japanese herbal) medicine, enhances mucosal IgA antibody response in mice immunized with antigen-entrapped biodegradable microparticles. Evid Based Complement Alternat Med 2010;7:69-77.

12 Kiyohara H, Nonaka K, Sekiya M: Polysaccharide-containing macromolecules in a Kampo (traditional Japanese herbal) medicine, Hochuekkito: dual active ingredients for modulation of immune functions on intestinal Peyer's patches and epithelial cells. Evid Based Complement Alternat Med 2009;1-12.

13 Gong T, Jiang Y, Wang Y: Recombinant mouse beta-defensin 2 inhibits infection by influenza A virus by blocking its entry. Arch Virol 2010;155:491-498.

-14 Selsted ME, Ouellettee AJ: Mammalian defensins in the antimicrobial immune response. Nat Immunol 2005;6:551-557.

15 Lehrer R: Primate defensins. Nat Rev Microbiol 2004;2:727-738.

16 Pazgier M, Hoover DM, Yang D: Human beta-defensins. Cell Mol Life Sci 2006;63:12941313.

17 Moser C, Weiner DJ, Lysenko E: $\beta$-Defensin 1 contributes to pulmonary innate immunity in mice. Infect Immunol 2002;70:3068-3072.

18 Bals R, Wang X, Meegalla RL: Mouse $\beta$-defensin 3 is an inducible antimicrobial peptide expressed in the epithelia of multiple organs. Infect Immunol 1999;67:3542-3547.

19 Murata H, Macauley J, Lewis AM Jr, Pedena $\mathrm{J}$ : Plaque purification as a method to mitigate the risk of adventitious-agent contamination in influenza vaccine virus seeds. Antivir Ther 2011;16:597-603.

20 Barchet W, Cella M, Odermatt B: Virus-induced interferon $\alpha$ production by a dendritic cell subset in the absence of feedback signaling in vivo. J Exp Med 2002;195:507-516.
21 Daffis S, Samuel MA, Keller BC, Gale M Jr, Diamond MS: Cell-specific IRF-3 responses protein against West Nile virus infection by interferon-dependent and -independent mechanisms. PloS Pathogens 2007;3:10051015.

22 Kamekura R, Kojima T, Takashima A: Thymic stromal lymphopoietin induces tight junction protein claudin-7 via NF- $\kappa B$ in dendritic cells. Histochem Cell Biol 2010;133: 339-348.

23 Garcia M, Dogusan Z, Moore F: Regulation and function of the cytosolic viral RNA sensor RIG-I in pancreatic beta cells. Biochim Biophys Acta 2009;1793:1768-1775.

24 Komuro A, Horvath CM: RNA- and virusindependent inhibition of antiviral signaling by RNA helicase LGP2. J Virol 2006;80: 12332-12342.

25 Wilden H, Fournier P, Zawatzky R: Expression of RIG-I, IRF3, IFN- $\beta$ and IRF7 determines resistance or susceptibility of cells to infection by Newcastle disease virus. Int J Oncol 2009;34:971-982.

26 Liu P, Lu M, Tian B: Expression of an IKKr splice variant determines IRF3 and canonical NF- $\kappa B$ pathway utilization in ssRNA virus infection. PloS One 2009;4:1-15.

27 Guleng B, Lian Y, Ren J: Mindin is upregulated during colitis and may activate NF- $\kappa \mathrm{B}$ in a TLR-9 mediated manner. World J Gastroenterol 2010;16:1070-1075.

28 Kato H, Sato S, Yoneyama M: Cell type-specific involvement of RIG-I in antiviral response. Immunity 2005;23:19-28.

29 Takeda K, Akira S: Toll-like receptors in innate immunity. Int Immunol 2005;17:1-14.

30 Wagner $\mathrm{H}$ : The immunobiology of the TLR9 subfamily. Trends Immunol 2004;25:381386.

31 Min L, Mohammad Isa SA, Shuai W, Piang CB, Nih FW, Kotaka M, Ruedl C: Cutting edge: granulocyte-macrophage colony-stimulating factor is the major CD8+ T cell-derived licensing factor for dendritic cell activation. J Immunol 2010;184:4625-4629. 